\title{
Xylo-oligosaccharide (XOS) in combination with inulin modulates both the intestinal environment and immune status in healthy subjects, while XOS alone only shows prebiotic properties
}

\author{
Jean-Michel Lecerf ${ }^{1 *}$, Flore Dépeint ${ }^{2}$, Elise Clerc $^{1}$, Yann Dugenet ${ }^{3}$, Claude N. Niamba ${ }^{2}$, Larbi Rhazi ${ }^{2}$, \\ Amélie Cayzeele ${ }^{1}$, Ghenwa Abdelnour ${ }^{2}$, Arnaud Jaruga ${ }^{1}$, Hassan Younes ${ }^{2}$, Heidi Jacobs ${ }^{4}$, \\ Guy Lambrey ${ }^{5}$, Afif M. Abdelnour ${ }^{2}$ and Philippe R. Pouillart ${ }^{2}$ \\ ${ }^{1}$ Nutrition Department, Institut Pasteur de Lille, 1 rue du Professeur Calmette, BP 245, 59019 Lille Cedex, France \\ ${ }^{2}$ Institut Polytechnique LaSalle Beauvais, 19 rue Pierre Waguet, BP 30313, 60026 Beauvais Cedex, France \\ ${ }^{3}$ Witaxos DF3 SAS/BioActor b.v. BioPartner Center, Oxfordlaan 70, 6229 EV Maastricht, The Netherlands \\ ${ }^{4}$ Cosucra - Groupe Warcoing, 1 rue de la Sucrerie, 7740 Warcoing, Belgium \\ ${ }^{5}$ Centre Hospitalier de Beauvais, 40 Avenue Léon Blum, 60000 Beauvais, France
}

(Submitted 11 July 2011 - Final revision received 23 November 2011 - Accepted 23 November 2011 - First published online 23 January 2012)

\section{Abstract}

The purpose of the present study was to establish the prebiotic effect of a new xylo-oligosaccharide (XOS) and of an inulin-and-XOS mixture (INU-XOS) and to determine their effect on endotoxaemia (lipopolysaccharides (LPS)) and immune parameters. In this randomised, parallel, placebo-controlled, double-blind study, sixty healthy volunteers were randomly assigned to three groups, receiving either $5 \mathrm{~g}$ XOS, INU-XOS ( $3 \mathrm{~g}$ inulin $+1 \mathrm{~g}$ XOS) or an equivalent weight of wheat maltodextrin (placebo) during 4 weeks. Faecal samples were collected to assess the effects of these products on microbiota, as well as SCFA composition, enzymatic activities and secretory IgA production. Circulating LPS was measured in plasma samples, and whole blood was incubated with LPS to measure cytokine expression. Consumption of XOS alone increased the faecal concentrations of Bifidobacterium and butyrate and activities of $\alpha$-glucosidase and $\beta$-glucuronidase, while decreasing the concentrations of acetate and $p$-cresol. Consumption of XOS in combination with inulin did not decrease the concentrations of acetate and $p$-cresol, but increased in addition the faecal concentrations of total SCFA and propionate. Furthermore, consumption of XOS in combination with inulin decreased LPS concentrations in blood and attenuated LPS-induced increases in gene expression in IL-1 $\beta$ and LPS-induced decreases in gene expression in IL-13 in blood. In conclusion, consumption of XOS alone or in combination with inulin results in beneficial albeit different changes in the intestinal microbiome on a high-fat diet. In addition, consumption of XOS in combination with inulin attenuates the proinflammatory effects of a high-fat diet in the blood of healthy subjects

Key words: Xylo-oligosaccharides: Immunonutrition: Prebiotics: Lipopolysaccharides: Cytokines

The complex role of the human intestinal microbiota is emerging and its functions are now more and more established when considering energy metabolism, nutrient digestion, vitamin synthesis, epithelial defences and immune responses ${ }^{(1)}$. The composition and function of the humanassociated microbiota are considered as a partner of the host in order to fight infection and to improve inflammatory processes and conditions. There is an increasing body of evidence linking the physiopathology of metabolic diseases such as obesity or inflammatory bowel disease and the gut microbiota ${ }^{(2)}$.

Through resistance to digestion in the upper gastrointestinal tract, non-digestible carbohydrates reach the colon intact to undergo a complete or partial fermentation in the large intestine. If they selectively stimulate the growth and/or the activity of the beneficial, health-promoting members of the gut microbiota, they meet the criteria of prebiotics $^{(3-6)} \cdot \beta(2 \rightarrow 1)$-Fructans, which include inulin and fructo-oligosaccharides (FOS), are considered to be prebiotics, while xylo-oligosaccharides (XOS) are considered as candidate prebiotics $^{(7)}$.

Mice fed a high-fat diet exhibited a significant increase in plasma lipopolysaccharides (LPS) defined as metabolic endotoxaemia $^{(8,9)}$ and a modified gut microbiota profile ${ }^{(10)}$. Bifidobacterium levels were significantly reduced in

\footnotetext{
Abbreviations: DP, degree of polymerisation; FOS, fructo-oligosaccharides; INU-XOS, mixture of inulin and xylo-oligosaccharides; s-IgA, secretory IgA; $\mathrm{V}_{1}$ measurement done on first day of treatment; $\mathrm{V}_{2}$, measurement done after 2 weeks of treatment; $\mathrm{V}_{3}$, measurement done after 4 weeks of treatment; XOS, xylo-oligosaccharides.
} 
high-fat-fed mice $v$. animals that received the standard high-carbohydrate diet ${ }^{(11)}$. In healthy men, a high-fat meal increases the baseline of LPS concentration, and low-grade endotoxaemia may contribute to the postprandial inflammatory state ${ }^{(12)}$. Obesity and insulin resistance are associated with low-grade chronic systemic inflammation ${ }^{(13,14)}$. Animal studies suggest that the development of obesity and associated low-grade inflammation could trigger the expression of inflammatory cytokines (e.g. TNF- $\alpha$ ) via a CD14/Toll-like receptor 4-dependent mechanism ${ }^{(15,16)}$. In mice fed a highfat diet, fructans supplementation induces a decrease in circulating LPS and pro-inflammatory cytokines ${ }^{(7,10)}$. Thus the gut microbiota could be implicated in obesity and insulin resistance through several mechanisms, including LPS-induced micro-inflammation.

Modulation of the immune function by prebiotics has not been fully investigated and most data originate from animal models. To our knowledge, there have been no studies published on the effect of prebiotics either on circulating LPS or simultaneously on cytokine expression in healthy human subjects consuming a stable fat-andcarbohydrate diet.

The aims of this study were (1) to establish the prebiotic effect of a new XOS compound and of a mixture of inulin and XOS (INU-XOS); and (2) to determine their role on endotoxaemia and immune parameters in healthy subjects consuming a normal and stable fat diet.

\section{Subjects and methods}

A total of sixty healthy volunteers (thirty-four women who declared not to be pregnant and twenty-six men) aged $18-24$ years $(20 \cdot 1$ (SEM 1.6$)$ years) participated in the study. They were students at the Institut Polytechnique LaSalle Beauvais. They were enrolled in October 2008 with the intervention phase through November to December 2008.

Volunteers were eligible for enrolment if they met all the inclusion criteria: stable weight; BMI $18.5-27 \mathrm{~kg} / \mathrm{m}^{2}$; fibre intake $13-18 \mathrm{~g} / \mathrm{d}$. Exclusion criteria were ongoing severe disease; gastrointestinal, bladder and pancreatic diseases; abdominal or gut surgery within the last 12 months; diarrhoea, constipation or recurrent abdominal pains; recent $(<3$ months) gastrointestinal food-borne illness; antibiotherapy or use of laxative drug within the last 6 months; diabetes mellitus; use of pre- or probiotic supplements; specific functional probiotic- or prebiotic-rich foods; alcohol consumption ( $>3$ drinks/d); orange juice intolerance.

The study was performed on-site at the Institut Polytechnique LaSalle Beauvais for the meals and at the Beauvais Hospital for samples collection. This study was conducted according to the guidelines laid down in the Declaration of Helsinki and all procedures involving human subjects were approved by the Regional Ethics Committee for North-West France based at the Lille University Hospital. Written informed consent was obtained from all participants at the time of recruitment and the study protocol (2007-A00273-50) was approved by the Regional Ethics Committee for North-West France based at the Lille University Hospital.

\section{Study design}

The study followed a randomised, parallel, placebocontrolled, double-blind design.

A semi-quantitative dietary survey was performed at enrolment in order to assess the usual dietary fibre intake in order to select the target population consuming $13-18 \mathrm{~g} / \mathrm{d}$. The volunteers were instructed to follow dietary guidelines to maintain their fibre intake during a 2 -week stabilisation phase and then throughout the intervention. As all volunteers were living on-site and taking all meals at the Institute cafeteria, the content of each meal could be closely controlled during the week. A $3 \mathrm{~d}$ dietary survey was performed at the end of the stabilisation period and repeated at the end of the intervention in order to assess the stability of the diet.

The sixty volunteers were randomly assigned to one of three groups. The first group (placebo) received a daily dose of $6.64 \mathrm{~g}$ of wheat maltodextrins (Glucidex $12 \mathrm{DE}$; Roquette Frères); the second group (XOS) received $6.64 \mathrm{~g}$ of a XOSenriched compound derived from wheat arabinoxylans (Opti'flor ${ }^{\circledR} ;$ DF3 SAS); and the third group (INU-XOS) received $6.64 \mathrm{~g}$ of a mixture containing inulin-type fructans (Fibruline ${ }^{\circledR}$ Instant; Cosucra-Groupe Warcoing), XOS (Opti'flor ${ }^{\circledR} ;$ DF3 SAS) and maltodextrins. Fibruline ${ }^{\circledR}$ Instant is a chicory inulin with a degree of polymerisation (DP) ranging from 2 to 60 and an average DP of about 10. Fibruline ${ }^{\circledR}$ Instant is a powder with a DM of $96 \%$ and contains (on DM) $90 \%$ of inulin. Opti'flor ${ }^{\circledR}$ is characterised by a DM of $95 \%$, a XOS content of $80 \%$ on DM, an average DP above 10 and by an arabinose: xylose ratio above 0.5 . These products were taken in two daily doses $(130 \mathrm{ml})$ before the breakfast and evening meal. The total daily dose of the active ingredient was $5 \mathrm{~g}$ XOS (XOS group) or $3 \mathrm{~g}$ inulin $+1 \mathrm{~g}$ XOS (INU-XOS group).

Products were prepared daily by addition to a commercially available orange juice (100\% pure juice, no pulp) and stored at $8^{\circ} \mathrm{C}$ before distribution. Products were ingested in front of an independent study monitor. For the weekend, products were prepared in quantity sufficient for $2 \mathrm{~d}$ and stored in a coolbox. Subjects collected the coolbox before leaving campus and signed a compliance form after consuming each dose. The taste of the three products (fibre or maltodextrins + juice) was assessed through organoleptic methods and was found not to be different.

\section{Data collection}

The measurements were done at inclusion $\left(\mathrm{V}_{0}\right)$, and then on the first day of treatment $\left(\mathrm{V}_{1}\right)$, after 2 weeks $\left(\mathrm{V}_{2}\right)$ and after 4 weeks $\left(\mathrm{V}_{3}\right)$ of treatment.

Clinical data. Weight, blood pressure and heart rate (two measurements after a 3 min rest) were assessed at inclusion, and then at $V_{1}, V_{2}$ and $V_{3}$. Gastrointestinal well-being was assessed at $V_{1}, V_{2}$ and $V_{3}$ with a visual-analogue rating scale for nine items including flatulence, bloating, rumbling, abdominal cramps, nausea, a global digestive tolerance score calculated from these five previous items, stool consistency, stool frequency, and general well-being through disturbances in usual and professional activities as well as 
disturbances in personal and social activities. The questionnaire was based on criteria measured by Paineau et $a l^{(17)}$. Items were scored on a linear scale measuring $10 \mathrm{~cm}$.

\section{Biological data}

Faecal samples. Faecal samples were collected at each visit $\left(\mathrm{V}_{1}\right.$ to $\left.\mathrm{V}_{3}\right)$ in an aseptic container. They were kept below $8^{\circ} \mathrm{C}$ and aliquoted within $6 \mathrm{~h}$ for the various tests before being stored at -20 or $-80^{\circ} \mathrm{C}$ until further analysis. $\mathrm{DM}, \mathrm{pH}$ and bacterial content were measured at each visit, SCFA were measured at $\mathrm{V}_{1}$ and $\mathrm{V}_{3}$, while $p$-cresol and phenol, $\alpha$-glucosidase and $\beta$-glucuronidase activities, and secretory IgA (s-IgA) were only measured at $\mathrm{V}_{3}$.

Blood samples. Blood samples were collected in heparinlined vacuum collection tubes $(7 \mathrm{ml})$ during visits $\mathrm{V}_{1}$ and $\mathrm{V}_{3}$. Whole blood was used to measure expression of cytokines after a LPS challenge. LPS is known to stimulate the expression of interferon- $\gamma$, TNF- $\alpha$, IL-1 $\beta$, IL- 8 and IL-12 while inhibiting IL-4, IL-10 and IL-13. TNF- $\alpha$ and IL-10 were measured both at $\mathrm{V}_{1}$ and $\mathrm{V}_{3}$, while the other cytokines were measured at $\mathrm{V}_{3}$ only. The remaining blood was then centrifuged $(3500 \mathrm{rpm}, 5 \mathrm{~min}$ ) and plasma collected to measure circulating LPS at $\mathrm{V}_{3}$.

\section{Measurements}

\section{Faecal measurements}

$D M$ and $p H$. Both DM and $\mathrm{pH}$ were measured on fresh samples. A $2 \mathrm{~g}$ sample was placed in a pre-weighted aluminium cup. The sample was heat-dried at $110^{\circ} \mathrm{C}$ for $1 \mathrm{~h}$, and then at $80^{\circ} \mathrm{C}$ for $48 \mathrm{~h}$ and placed in a desiccator to cool down, after which the DM was weighed. A $0.5 \mathrm{~g}$ sample was homogenised in $5 \mathrm{ml}$ double distilled water (deionised water) before measuring the $\mathrm{pH}$.

Total microbiota and composition. Total bacterial count and specific bacterial profile were analysed by quantitative PCR, as described by Pouillart et al. ${ }^{(18)}$. DNA was extracted from $200 \mathrm{mg}$ of faecal sample using the QiaAmp DNA stool mini kit (Qiagen) according to the manufacturer's instructions. Then, $100 \mathrm{ng}$ of DNA from each sample were amplified using selected primers and probe sets detailed in Table 1 or previously published ${ }^{(18)}$.
Cycle quantification data were quantified against standard curves using selected bacterial strains. Data were expressed as $\log _{10}$ (copy number)/g DM.

SCFA (C2 (acetic acid), C3 (propionic acid), C4 (butyric acid)). Volatile fatty acids were extracted and measured according to Scheppach et al. ${ }^{(19)}$ with some variants. A $2 \mathrm{~g}$ sample was homogenised in $5 \mathrm{ml}$ double distilled water and then centrifuged at $4500 \mathrm{~g}$ for $5 \mathrm{~min}$. The supernatant was acidified to $\mathrm{pH} 2$ using $25 \mu \mathrm{l}$ of $\mathrm{H}_{2} \mathrm{SO}_{4}(2 \mathrm{M})$ and injected into a BP21 gas chromatography column (length: $30 \mathrm{~m}$, inner diameter: $530 \mu \mathrm{m}$, film: $1 \mu \mathrm{m}$ ) along with an internal standard (4-hydroxy-4-methyl-2-pentanone). $\mathrm{H}_{2}$ was supplied as the carrier gas at a flow rate of $1.5 \mathrm{ml} / \mathrm{min}$. The initial oven temperature was $135^{\circ} \mathrm{C}$ and was kept there for $6 \mathrm{~min}$, and then raised to $180^{\circ} \mathrm{C}$ by $25^{\circ} \mathrm{C} / \mathrm{min}$ and held there for $1 \mathrm{~min}$, and then further increased to $230^{\circ} \mathrm{C}$ by $25^{\circ} \mathrm{C} / \mathrm{min}$, and finally held at $230^{\circ} \mathrm{C}$ for $1 \mathrm{~min}$. Glass wool (Supelco) was inserted in the glass liner of the split injection port. The temperatures of the flame ionisation detector and the injection port were 240 and $280^{\circ} \mathrm{C}$, respectively. The flow rates of $\mathrm{H}_{2}$ and air as make-up gas were 40 and $400 \mathrm{ml} / \mathrm{min}$, respectively. The injected sample volume for GC (AutoSystem XL; PerkinElmer) analysis was $1 \mu \mathrm{l}$, and the running time for each analysis was about $10 \mathrm{~min}$. The different SCFA were identified according to the retention time of the various elution peaks. Quantification was obtained by comparison to a standard curve.

p-Cresol and phenol. The p-cresol and phenol were determined following the techniques established previously ${ }^{(20)}$.

$\alpha$-Glucosidase and $\beta$-glucuronidase activities. The enzyme activities were measured as described by Djouzi et al. ${ }^{(21)}$ with some modifications. A $1 \mathrm{~g}$ sample was homogenised in $10 \mathrm{ml}$ of $0.1 \mathrm{M}$-potassium phosphate buffer, $\mathrm{pH} 7 \cdot 2$ and sonicated for $30 \mathrm{~s}$ before centrifugation at $10000 \boldsymbol{g}$ for $20 \mathrm{~min}$ at $4{ }^{\circ} \mathrm{C}$. The supernatant was collected and incubated for $15 \mathrm{~min}$ at $30^{\circ} \mathrm{C}$ with an equal volume of $4 \mathrm{~mm}$ substrate. The reaction was stopped on ice with potassium carbonate $(1 \mathrm{M})$ in double distilled water. Absorbance at $400 \mathrm{~nm}$ was plotted against a standard curve of $p$-nitrophenyl to measure the production rate of the reaction, and thus the enzymatic activity. Specific substrates were $p$-nitrophenyl- $\alpha$-D-glucopyranoside

Table 1. Details of primers and probes used in quantitative PCR to amplify $16 \mathrm{~s}$ rRNA

\begin{tabular}{lll}
\hline Genus & Primers and probes* & Primers and probes sequences $\left(5^{\prime}-3^{\prime}\right) \dagger$ \\
\hline Firmicutes spp. & Firm-F & GAATCTTCCACAATGGACGAAAG \\
& Firm-R & AATACCGTCAATACCTGAACAGTTACTC \\
Faecalibacterium prausnitzii & Firm-MGB probe & 6FAM-CTGATGGAGCAACGCCGCGT \\
& Frau-F & GGCCTACTGGGCACCAACT \\
& Fprau-R & AATCCTGTTTGCTACCCACACTTT \\
Roseburia spp. & Frau-MGB probe & 6FAM-ACGCTGAGGCTCG \\
& Ros-F & TGTAGCGGTGAAATGCGTAGA \\
& Ros-R & GCTCCCCACGCTTTCGA \\
Bacteroidetes spp. & Ros-MGB probe & 6FAM-ACTGAGACACGGCCCA \\
& Bacte-F & AAGGTCCCCACATTGGAA \\
& Bacte-R & CTGCTGCCTCCCGTAGGA \\
& Bacte-MGB probe & 6FAM-CTGAGACACGGTCCAAA \\
\hline
\end{tabular}

* Primer and probe choice was established using the following website: www.ncbi.nlm.nih.gov/BLAST/

†Primers and probes were validated in silico against the sequence of all known bacterial strains (ncbi/BLAST, 2004-5) and in vitro for cross-reactivity against the full panel of reference strains. 
for $\alpha$-glucosidase and $p$-nitrophenyl- $\beta$-D-glucuronide for $\beta$-glucuronidase.

Secretory $\operatorname{IgA}$. A $100 \mathrm{mg}$ sample was homogenised and processed using the s-IgA ELISA kit (Immunodiagnostik) according to the instruction manual.

Other biological measurements

Cytokines. Whole blood samples were incubated with $1 \mathrm{ng} / \mathrm{ml} \mathrm{LPS}$ at $37^{\circ} \mathrm{C}$ for $6 \mathrm{~h}(\mathrm{TNF}-\alpha)$ and $24 \mathrm{~h}$ (all other cytokines) in a rolling incubator. One reference sample was incubated without $\operatorname{LPS}^{(22)}$. Incubation was stopped by adding $500 \mu \mathrm{l}$ of QIAzol (Qiagen). Total RNA was isolated using the RNeasy lipid mini kit (Qiagen) according to the user manual. Recombinant complementary DNA was obtained from $100 \mathrm{ng}$ of RNA using the Quantitect reverse transcriptase kit (Qiagen) according to the user manual. Finally, $100 \mathrm{ng}$ complementary DNA was amplified against designed primer sets (Applied Biosystems). Relative expression for the cytokines was calculated against the untreated reference sample. Both $\beta$-actin and peptidylprolyl isomerise A were used as reference genes. For all genes, efficiency of the quantitative PCR was between 96 and $106 \%$.

Lipopolysaccharides. Circulating LPS was measured in plasma samples using the limulus amebocyle lysate chromogenic endpoint assay (Hycult) according to the manufacturer's instructions.

Dietary intakes. The $3 \mathrm{~d}$ food diary was completed twice (before randomisation $\left(\mathrm{V}_{1}\right)$ and before the end of the study $\left(\mathrm{V}_{3}\right)$ ) by the volunteers and assessed by the study dietitian. The food and nutrient table was produced through the Nutrilog ${ }^{\circledR}$ software (Nutrilog SAS) based on the French food composition database available in $\mathrm{CIQUAL}^{(23)}$.

\section{Determination of sample size and statistical analysis}

Sample size determination. The number of subjects per group was calculated for the primary end-point which was a significative variation of the Bifidobacterium population expressed in log (copies/g DM).

Previous studies using FOS or inulin have shown that the variability of the main objective is one log unit (colonyforming units/g); so standard deviation is set to 1 . Bouhnik et $a{ }^{(24)}$ have stated that a clinical significant effect on Bifidobacterium requires a difference of $1 \log$ (colony-forming units/g) between subjects taking placebo and subjects taking $10 \mathrm{~g}$ of inulin. We expected, based on our previous unpublished results (Y. Dugenet, personal communication), that the test products at the selected dose would be as effective as $10 \mathrm{~g}$ of inulin. So, for a type I error rate $\alpha$ of $5 \%$ and for a type II error rate $\beta$ of $20 \%$, the minimum number of subjects required for two-sided testing is sixteen. Because of the possible dropout of subjects and in order to increase the statistical power, the final number chosen was twenty subjects per group.

Data handling. Whenever possible, relative changes between baseline and the end of the 4-week intervention were calculated as percentage of baseline values. This was the case for clinical, dietetic and some biological parameters as listed in Table 2 (baseline characteristics). For digestive tolerance symptoms, the nature of the text (self-assessment on a $10 \mathrm{~cm}$ scale) led to some baseline values of 'zero', preventing any calculation for relative changes from baseline. Instead, the absolute changes were calculated and used. For all other parameters where only the end-point was measured, those absolute data were used.

Data analysis. Data analysis was performed using the statistical package SPSS ${ }^{\circledR}$ version 17.0 for Windows (SPSS, Inc.). Descriptive analyses were done for all parameters and are given as means and standard errors. All statistical tests were two-sided with a significance level of $0 \cdot 05$. Normality of data distribution for each parameter was assessed by ShapiroWilk test before performing either parametric ( $t$ tests) or non-parametric (Mann-Whitney test or Wilcoxon signedrank test) tests to compare groups or visits.

\section{Results}

A total of sixty subjects were included in the study, but one subject dropped out at $\mathrm{V}_{1}$ and was not replaced. No further subject dropout occurred during the study. Groups are homogeneous for all measured parameters at baseline, except for the sex ratio (Table 2). It was considered that none of the tested markers would be influenced by sex; this factor was therefore not included as a randomisation criteria.

Dietary fibre intake (excluding test product) decreased in the XOS group from $13.91(\mathrm{SEM} 0.87) \mathrm{g} / \mathrm{d}$ at $\mathrm{V}_{1}$ to 12.08 (SEM $0.59) \mathrm{g} / \mathrm{d}$ at $\mathrm{V}_{3}(P=0.029)$. However, we can observe from Table 3 that there was no significant difference in the study outcome between groups on any of the clinical or dietary parameters.

The global digestive tolerance symptoms score based on the sum of five symptoms was increased at $\mathrm{V}_{2}$ in INU-XOS compared to the placebo and XOS groups $(P=0.005$ and 0.046 , respectively), but was only transient as the scores decreased at $\mathrm{V}_{3}$ for the INU-XOS group $\left(P=0.007\right.$ between $V_{2}$ and $\mathrm{V}_{3}$ ). INU-XOS increased flatulence and bloating sensations at $\mathrm{V}_{2}(P=0.001$ and 0.013 , respectively $)$ and $\mathrm{V}_{3}(P=0.004$ and 0.029 , respectively) compared to placebo. However, when comparing groups for relative changes in tolerance symptoms (Table 4), only flatulence was significantly increased between the placebo and INU-XOS groups over the intervention period $(P=0 \cdot 032)$.

Similarly, stool consistency was perceived as more liquid in the INU-XOS group than in the placebo group $(P=0.001)$ at $\mathrm{V}_{2}$ with a decrease in stool consistency between $\mathrm{V}_{1}$ and $\mathrm{V}_{2}$ $(P=0 \cdot 002)$ and a return to baseline at $\mathrm{V}_{3}(P=0 \cdot 011)$. No differences were observed for self-reported daily stool frequency except for an increase between $\mathrm{V}_{1}$ and $\mathrm{V}_{2}$ in the INU-XOS group from 1.09 (SEM $0 \cdot 12$ ) to 1.55 (SEM $0 \cdot 25$ ) stool $/ \mathrm{d}$ $(P=0.026)$. No group difference was observed for relative or absolute changes in either of those parameters.

We observed a small impairment in general well-being $(P=0.026)$ and professional activities $(P=0.038)$ for the INU-XOS group in comparison to the placebo group at $V_{3}$. Prebiotic activity is characterised by both changes in the microbial profile and bacterial metabolic activity. 
Table 2. Baseline characteristics of the target population*

(Mean values with their standard errors)

\begin{tabular}{|c|c|c|c|c|c|c|}
\hline & \multicolumn{2}{|c|}{ Placebo } & \multicolumn{2}{|c|}{ xos } & \multicolumn{2}{|c|}{ INU-XOS } \\
\hline & Mean & SEM & Mean & SEM & Mean & SEM \\
\hline \multicolumn{7}{|l|}{ Demographics } \\
\hline Age (years) & $20 \cdot 0$ & 0.4 & $20 \cdot 1$ & 0.4 & $20 \cdot 1$ & 0.4 \\
\hline Sex ratio $(M / F)$ & $7 / 13$ & - & $5 / 14$ & - & $14 / 6$ & - \\
\hline Weight (kg) & $63 \cdot 0$ & $2 \cdot 0$ & $60 \cdot 3$ & $2 \cdot 4$ & 65.9 & $2 \cdot 8$ \\
\hline $\mathrm{BMI}\left(\mathrm{kg} / \mathrm{m}^{2}\right)$ & 21.6 & 0.5 & $20 \cdot 9$ & 0.6 & 21.4 & 0.5 \\
\hline Heart rate (bpm) & $69 \cdot 9$ & 1.8 & $66 \cdot 2$ & $2 \cdot 1$ & $68 \cdot 1$ & $2 \cdot 1$ \\
\hline \multicolumn{7}{|l|}{ Dietetics } \\
\hline Energy (kJ) & $7941 \cdot 0$ & 376.6 & 7903.5 & 477.0 & $7736 \cdot 0$ & 493.7 \\
\hline Protein $(\mathrm{g})$ & $77 \cdot 4$ & 3.9 & $76 \cdot 2$ & 3.9 & $80 \cdot 4$ & $5 \cdot 6$ \\
\hline Lipid (g) & $75 \cdot 0$ & 4.9 & 74.7 & $5 \cdot 8$ & $69 \cdot 1$ & $6 \cdot 7$ \\
\hline Carbohydrate (g) & $216 \cdot 0$ & 9.4 & $210 \cdot 2$ & $13 \cdot 3$ & 218.4 & $12 \cdot 2$ \\
\hline Fibre (g) & $13 \cdot 7$ & 0.9 & 13.9 & 0.9 & $12 \cdot 9$ & 0.8 \\
\hline \multicolumn{7}{|l|}{ Tolerance } \\
\hline Flatulence (cm on scale) & $2 \cdot 23$ & 0.41 & $2 \cdot 34$ & 0.46 & $2 \cdot 64$ & 0.41 \\
\hline Bloating (cm on scale) & $1 \cdot 17$ & 0.23 & 1.00 & 0.44 & 1.44 & 0.40 \\
\hline Rumbling (cm on scale) & 1.97 & 0.45 & 2.32 & 0.45 & 2.64 & 0.40 \\
\hline Cramps (cm on scale) & 0.68 & 0.27 & 0.55 & 0.31 & 0.78 & 0.32 \\
\hline Nausea (cm on scale) & 0.37 & $0 \cdot 15$ & 0.47 & 0.23 & 0.84 & 0.37 \\
\hline Stool consistency (cm on scale) & 0.4 & 0.37 & 0.84 & 0.64 & 0.55 & 0.34 \\
\hline Stool frequency (stool/d) & $1 \cdot 12$ & $0 \cdot 10$ & 1.14 & $0 \cdot 10$ & 1.09 & 0.12 \\
\hline \multicolumn{7}{|l|}{ Prebiotic effect } \\
\hline DM (\%) & 29.5 & 1.6 & $27 \cdot 7$ & 1.7 & $28 \cdot 7$ & 1.5 \\
\hline pH (arbitrary units) & $6 \cdot 90$ & 0.11 & $6 \cdot 84$ & 0.08 & 6.90 & 0.14 \\
\hline \multicolumn{7}{|l|}{ SCFA } \\
\hline $\mathrm{C} 2(\mu \mathrm{mol} / \mathrm{g} \mathrm{DM})$ & 189.4 & $14 \cdot 2$ & 203.5 & 9.6 & $203 \cdot 2$ & $14 \cdot 2$ \\
\hline C3 $(\mu \mathrm{mol} / \mathrm{g} \mathrm{DM})$ & $55 \cdot 2$ & 4.7 & 55.4 & $2 \cdot 6$ & $59 \cdot 1$ & 4.4 \\
\hline C4 ( $\mu \mathrm{mol} / \mathrm{g} \mathrm{DM})$ & 50.5 & 4.9 & $52 \cdot 3$ & 2.5 & $54 \cdot 2$ & $3 \cdot 8$ \\
\hline C3:C2 ratio & 0.29 & 0.01 & 0.28 & 0.01 & 0.29 & 0.01 \\
\hline \multicolumn{7}{|l|}{ SCFA } \\
\hline C2 (\% of total SCFA) & $64 \cdot 7$ & $1 \cdot 1$ & $65 \cdot 3$ & 0.9 & 64.4 & 0.6 \\
\hline C3 (\% of total SCFA) & $18 \cdot 6$ & 0.4 & $17 \cdot 9$ & 0.4 & $18 \cdot 6$ & 0.3 \\
\hline C4 (\% of total SCFA) & $16 \cdot 7$ & 0.8 & $16 \cdot 8$ & 0.5 & $17 \cdot 0$ & 0.4 \\
\hline \multicolumn{7}{|l|}{ Microbiota } \\
\hline Bifidobacterium $\left(\log _{10}\right.$ (copies)/g DM) & $6 \cdot 36$ & $0 \cdot 17$ & $6 \cdot 54$ & 0.3 & $6 \cdot 46$ & 0.22 \\
\hline Lactobacillus ( $\log _{10}$ (copies)/g DM) & $5 \cdot 58$ & 0.21 & 5.73 & 0.13 & 5.41 & 0.14 \\
\hline Peptostreptococcus $\left(\log _{10}\right.$ (copies)/g DM) & 2.95 & 0.14 & $2 \cdot 76$ & 0.21 & 3.01 & 0.20 \\
\hline Clostridium $\left(\log _{10}\right.$ (copies)/g DM) & 7.46 & $0 \cdot 10$ & 7.54 & 0.12 & $7 \cdot 61$ & 0.12 \\
\hline \multicolumn{7}{|l|}{ Immune modulation } \\
\hline TNF- $\alpha$ (relative expression) & 3.04 & 0.44 & 3.38 & 0.59 & 3.45 & 0.45 \\
\hline IL-10 (relative expression) & -2.39 & 0.52 & $-2 \cdot 3$ & 0.59 & $-1 \cdot 18$ & 0.65 \\
\hline
\end{tabular}

XOS, xylo-oligosaccharide; INU-XOS, inulin-and-XOS mixture; M, male; F, female; bpm, beats/min.

${ }^{*}$ All groups are homogeneous at baseline $(P>0.05)$.

Bifidobacterium population was higher at $\mathrm{V}_{2}$ and $\mathrm{V}_{3}$ $(P=0.003$ and $<0.001$, respectively) in the XOS group, and at $\mathrm{V}_{2}$ and $\mathrm{V}_{3}(P=0.015$ and $0 \cdot 001$, respectively $)$ in the INU-XOS group compared to placebo. The differences were clinically pertinent of about $1 \mathrm{log}$. There was a moderate increase of the Lactobacillus population between $\mathrm{V}_{1}$ and $\mathrm{V}_{2}$ (about $0.5 \mathrm{log})$ in the INU-XOS group $(P=0.048)$. The Peptostreptococcus population had increased $(1 \log )$ at $\mathrm{V}_{2}$ in the XOS $(P=0.027)$ and INU-XOS groups $(P=0.047)$ as compared to the placebo, but both groups returned to baseline at $\mathrm{V}_{3}$. Analysis of the changes from baseline to end of the study only showed a significant effect of both groups against placebo for Bifidobacterium (Table 5). There was no difference between the three groups for Clostridium population at all time points. However, there was a significant overall decrease between $\mathrm{V}_{1}$ and $\mathrm{V}_{3}$ in the three groups $(P<0 \cdot 001)$, possibly due to increased orange juice consumption. For Firmicutes, Bacteroidetes, Faecalibacterium prausnitzii and Rosebusia spp. populations, there was no difference between the three groups at $\mathrm{V}_{3}$.

Bacterial metabolism can be measured by its products (carbohydrate or protein metabolites), its activity (enzymatic) or the impact on the gut environment $(\mathrm{pH})$. Faecal $\mathrm{pH}$ was lower in the XOS than in the placebo group at $\mathrm{V}_{3}(6.47$ (SEM $0.17) v .6 .97$ ( $\operatorname{sem} 0.15$ ); $P=0.033$ ), but changes from baseline showed no significant difference between the two groups (Table 6). As expected, carbohydrate metabolism was affected.

Total SCFA production was significantly increased at $\mathrm{V}_{3}$ in the INU-XOS group $(P=0.028)$ as compared to placebo. No variation in the total production was observed in the XOS group. SCFA profile, however, was modified in both groups. At $\mathrm{V}_{3}$, both the propionic and butyric acid contributions were higher in the XOS and INU-XOS groups $(P<0.001$ each), and acetic acid was lower in the two treatment groups $(P<0.001)$ as compared to placebo. This was 
Table 3. Clinical and dietetic parameters at $V_{3}$ (measurement done after 4 weeks of treatment); changes from baseline (percentage change)

(Mean values with their standard errors)

\begin{tabular}{|c|c|c|c|c|c|c|c|c|}
\hline & \multicolumn{2}{|c|}{ Placebo } & \multicolumn{2}{|c|}{ xos } & \multirow[b]{2}{*}{$P$} & \multicolumn{2}{|c|}{ INU-XOS } & \multirow[b]{2}{*}{$P$} \\
\hline & Mean & SEM & Mean & SEM & & Mean & SEM & \\
\hline \multicolumn{9}{|l|}{ Clinical } \\
\hline Weight (kg) & -0.1 & 0.4 & -0.2 & 0.3 & 0.759 & 0.0 & 0.4 & 0.872 \\
\hline Heart rate (bpm) & -5.4 & 2.5 & -0.9 & $2 \cdot 8$ & 0.240 & 0.1 & $2 \cdot 3$ & 0.112 \\
\hline \multicolumn{9}{|l|}{ Dietetics } \\
\hline Total energy intake $(\mathrm{kJ})$ & 3.5 & $5 \cdot 1$ & 4.9 & $7 \cdot 2$ & 0.811 & $6 \cdot 3$ & 4.4 & 0.674 \\
\hline Protein $(\mathrm{g})$ & 7.4 & $5 \cdot 8$ & $13 \cdot 2$ & $7 . \overline{3}$ & 0.465 & 3.0 & 4.4 & 0.760 \\
\hline Lipid (g) & $7 \cdot 3$ & 4.7 & 3.8 & 7.6 & 0.861 & 9.7 & $6 \cdot 3$ & 0.177 \\
\hline Carbohydrate (g) & 0.2 & 6.9 & -1.7 & $7 \cdot 6$ & 0.555 & $14 \cdot 2$ & $7 \cdot 6$ & 0.544 \\
\hline Fibre $(\mathrm{g})$ & -7.9 & $5 \cdot 4$ & $-11 \cdot 8$ & $6 \cdot 1$ & 0.633 & 9.8 & 11.5 & 0.516 \\
\hline
\end{tabular}

XOS, xylo-oligosaccharide; INU-XOS, inulin-and-XOS mixture; bpm, beats/min.

supported by highly significant changes from baseline in both groups for C2, C3 and C4 profiles (Table 6). The contribution as raw SCFA production was different as shown in Table 6 , with XOS effect due to decreased $\mathrm{C} 2$ production and INU-XOS due to increased $\mathrm{C} 4$ production. In both groups, the $\mathrm{C} 3: \mathrm{C} 2$ ratio was more increased compared to placebo (Table 6). Protein metabolism was only affected for $p$-cresol in the XOS group at $\mathrm{V}_{3}(39.64(\operatorname{sem} 3.43) \mu \mathrm{g} / \mathrm{g} \mathrm{DM} P=0.020)$ as compared to placebo $(56 \cdot 21(\operatorname{sem} 5 \cdot 90) \mu \mathrm{g} / \mathrm{g}$ DM). Finally, bacterial enzymatic activity was increased in both groups compared to placebo at $\mathrm{V}_{3}$ (Table 6).

Immunomodulatory activity of the test products was measured both by direct and indirect markers. There was a $70 \%$ higher faecal expression of s-IgA at $\mathrm{V}_{3}$ in the INU-XOS group compared to the placebo group, which was non-significant. Circulating LPS, however, was significantly decreased at $\mathrm{V}_{3}$ compared to placebo (Table 7).

Indirect measures of immune modulation were done by stimulating whole blood with a proinflammatory factor (LPS) and comparing the expression of RNA for cytokine production. The gene expression for selected cytokines, representative of both pro- and anti-inflammatory pathways, was measured by comparison with a non-stimulated sample.

The overall effect was a pro-inflammatory response to LPS incubation, which was significantly inhibited in the INU-XOS group for IL-1 $\beta$ compared to placebo (Table 7). LPS response for the other pro-inflammatory cytokines was not modulated.

Anti-inflammatory cytokine expression was partially restored for IL-13 in the INU-XOS group compared to placebo. LPS response was not modulated for IL-4. XOS did not affect the LPS-induced ex vivo inflammation profile.

Globally, a decrease of the 'pro-inflammatory' Th1 pathway (IL- $\beta$ ) and a stimulation of the 'anti-inflammatory' Th2/Treg pathways (IL-13) were observed for INU-XOS only. Linear regression analysis was performed to investigate whether circulating LPS concentrations could be a confounding factor in the cytokine response. Results showed that this was not the case either for IL-1 $\beta$ or for IL-13.

Table 4. Parameters linked to digestive tolerance at $V_{3}$ (measurement done after 4 weeks of treatment); for the different symptoms, absolute changes ( $\mathrm{cm}$ change) are presented and used for comparison†

(Mean values with their standard errors)

\begin{tabular}{|c|c|c|c|c|c|c|c|c|}
\hline & \multicolumn{2}{|c|}{ Placebo } & \multicolumn{2}{|c|}{ xos } & \multirow[b]{2}{*}{$P$} & \multicolumn{2}{|c|}{ INU-XOS } & \multirow[b]{2}{*}{$P$} \\
\hline & Mean & SEM & Mean & SEM & & Mean & SEM & \\
\hline \multicolumn{9}{|l|}{ Absolute changes } \\
\hline Flatulence & -0.29 & 0.40 & 0.49 & 0.46 & 0.261 & 1.64 & 0.70 & $0.032^{\star}$ \\
\hline Bloating & -0.47 & 0.23 & 0.08 & 0.50 & 0.192 & 0.34 & 0.49 & 0.375 \\
\hline Rumbling & -0.83 & 0.45 & -0.62 & 0.39 & 0.955 & -0.12 & 0.64 & 0.968 \\
\hline Cramps & -0.41 & 0.20 & 0.17 & 0.47 & 0.354 & -0.56 & 0.35 & 0.264 \\
\hline Nausea & -0.13 & 0.12 & -0.21 & 0.27 & 0.818 & -0.68 & -0.38 & 0.481 \\
\hline Sum of all symptoms & $-2 \cdot 13$ & 0.56 & -0.08 & 1.44 & 0.209 & 0.62 & 1.62 & 0.115 \\
\hline Stool consistency & -0.12 & 0.47 & -1.07 & 0.53 & 0.197 & $-1 \cdot 16$ & 0.52 & 0.139 \\
\hline \multicolumn{9}{|l|}{ Relative changes } \\
\hline Stool frequency & $15 \cdot 0$ & $10 \cdot 3$ & $9 \cdot 2$ & $12 \cdot 0$ & 0.723 & $30 \cdot 2$ & 21.9 & 0.670 \\
\hline \multicolumn{9}{|l|}{ Comfort appreciation } \\
\hline General & $2 \cdot 98$ & 0.48 & 3.59 & 0.52 & 0.397 & 4.36 & 0.35 & $0.026^{\star}$ \\
\hline Professional & $0 \cdot 16$ & 0.07 & 0.31 & $0 \cdot 18$ & 0.545 & 0.66 & 0.22 & $0.038^{*}$ \\
\hline Social & $0 \cdot 12$ & 0.04 & 0.32 & $0 \cdot 18$ & 0.295 & 0.44 & 0.19 & 0.098 \\
\hline
\end{tabular}

XOS, xylo-oligosaccharide; INU-XOS, inulin-and-XOS mixture.

${ }^{*}$ Mean values were significantly different compared to the placebo group $(P<0.05)$.

$\dagger$ For frequency of stool production, relative changes (percentage change) could be calculated and are presented. For those comfort questions only measured at $V_{3}$, the absolute values are presented. 
Table 5. Microbiota profile parameters at $V_{3}$ (measurement done after 4 weeks of treatment); changes from baseline (percentage change) for those bacterial species measured at $V_{1}$ (measurement done on first day of treatment) $\dagger$

(Mean values with their standard errors)

\begin{tabular}{|c|c|c|c|c|c|c|c|c|}
\hline & \multicolumn{2}{|c|}{ Placebo } & \multicolumn{2}{|c|}{ xos } & \multirow[b]{2}{*}{$P$} & \multicolumn{2}{|c|}{ INU-XOS } & \multirow[b]{2}{*}{$P$} \\
\hline & Mean & SEM & Mean & SEM & & Mean & SEM & \\
\hline \multicolumn{9}{|l|}{ Microbiota changes } \\
\hline Bifidobacterium & 0.7 & $2 \cdot 8$ & $28 \cdot 6$ & $16 \cdot 0$ & $0.002^{* *}$ & $16 \cdot 0$ & 3.8 & $0.009^{*}$ \\
\hline Lactobacillus & $2 \cdot 8$ & 4.0 & 1.0 & $2 \cdot 3$ & 0.706 & $7 \cdot 7$ & 5.5 & 0.467 \\
\hline Peptostreptococcus & -4.9 & $9 \cdot 2$ & $28 \cdot 0$ & $17 \cdot 4$ & 0.227 & $3 \cdot 1$ & $10 \cdot 4$ & 0.565 \\
\hline Clostridium & $-7 \cdot 7$ & $1 \cdot 1$ & -6.7 & 1.8 & 0.933 & -7.5 & 1.0 & 0.865 \\
\hline \multicolumn{9}{|l|}{ Absolute bacteria profile } \\
\hline Firmicutes & $10 \cdot 11$ & 0.06 & $10 \cdot 15$ & 0.06 & 0.673 & $10 \cdot 17$ & 0.05 & 0.561 \\
\hline Bacteroidetes & 4.86 & 0.14 & 5.26 & 0.24 & 0.064 & 5.04 & 0.22 & 0.449 \\
\hline Faecalibacterium prausnitzii & 8.66 & 0.95 & 8.74 & 0.10 & 0.575 & $8 \cdot 74$ & 0.09 & 0.537 \\
\hline Roseburia spp. & 9.02 & 0.09 & 9.07 & 0.11 & 0.680 & 9.23 & 0.08 & 0.240 \\
\hline
\end{tabular}

XOS, xylo-oligosaccharide; INU-XOS, inulin-and-XOS mixture.

${ }^{\star *}$ Values were significantly different compared to the placebo group $(P<0.01)$.

$\dagger$ For other bacteria, the absolute values at $V_{3}\left(\log _{10}(\right.$ copies $) / g$ of faecal DM) are compared.

\section{Discussion}

There was no difference between the three groups for clinical, anthropometric and nutritional data. No weight change was observed in these normal-weight subjects. Throughout the study, the diet remained unchanged with a $35 \%$ fat and stable fibre intake (about $13 \mathrm{~g} / \mathrm{d}$ ); it may be considered as a typical (standard) Western high-fat, low-fibre diet. The small drop in fibre intake in the XOS group at $\mathrm{V}_{3}$ can only reinforce the knowledge that any effect observed was due to the test compound rather than the fibres of dietary origin.

The primary objective of the present study was to investigate the prebiotic properties of the two test products. Inulin is a fructan molecule composed of $\beta(2 \rightarrow 1)$-linked fructose monomers, ending or not by a glucose unit. This specific conformation gives the property of non-digestibility by human salivary, gastric and enteric enzymes ${ }^{(25)}$. The bifidogenic effect of inulin is well established ${ }^{(26-29)}$ and inulin is defined as a prebiotic ${ }^{(3-5)}$. Arabinoxylans are the main polysaccharides in hemicellulose. Their molecular weight varies from 600 to $1300 \mathrm{Da}$ (with a DP between 5 and 10) up to $500000 \mathrm{Da}$ (DP 3500-4000). Wheat arabinoxylans include a linear backbone of $\beta(1 \rightarrow 4)$-linked $\mathrm{D}$-xylopyranosyl units, which are either non-substituted, mono- or bi-substituted with L-arabinofuranosyl units. Some of the arabinose residues are esterified by phenolic acids, essentially ferulic acid. The bifidogenic effect of XOS was demonstrated in some

Table 6. Parameters linked to the prebiotic effect at $V_{3}$ (measurement done after 4 weeks of treatment) $\dagger$ (Mean values with their standard errors)

\begin{tabular}{|c|c|c|c|c|c|c|c|c|}
\hline & \multicolumn{2}{|c|}{ Placebo } & \multicolumn{2}{|c|}{ xos } & \multirow[b]{2}{*}{$P$} & \multicolumn{2}{|c|}{ INU-XOS } & \multirow[b]{2}{*}{$P$} \\
\hline & Mean & SEM & Mean & SEM & & Mean & SEM & \\
\hline \multicolumn{9}{|l|}{ Basic parameters } \\
\hline DM & -9.3 & $7 \cdot 0$ & $1 \cdot 2$ & 7.9 & 0.337 & $3 \cdot 6$ & $4 \cdot 8$ & 0.135 \\
\hline $\mathrm{pH}$ & $1 \cdot 2$ & 1.9 & $-5 \cdot 3$ & $2 \cdot 4$ & 0.116 & -3.5 & $2 \cdot 1$ & 0.100 \\
\hline \multicolumn{9}{|l|}{ SCFA } \\
\hline C2 concentration & 14.5 & 8.2 & -13.4 & $6 \cdot 1$ & $0.011^{\star}$ & 11.4 & $10 \cdot 1$ & 0.552 \\
\hline C3 concentration & $13 \cdot 2$ & $9 \cdot 7$ & $17 \cdot 3$ & 8.5 & 0.753 & $32 \cdot 8$ & $12 \cdot 8$ & 0.291 \\
\hline C4 concentration & $19 \cdot 9$ & $14 \cdot 6$ & $37 \cdot 0$ & $9 \cdot 8$ & 0.136 & $61 \cdot 2$ & $16 \cdot 4$ & $0.028^{*}$ \\
\hline C3:C2 ratio & -0.9 & 4.8 & 37.9 & $6 \cdot 1$ & $0.000^{* *}$ & $19 \cdot 4$ & $2 \cdot 9$ & $0.001^{\star \star}$ \\
\hline C2 profile & $1 \cdot 7$ & 1.9 & -13.5 & 1.6 & $0.000^{* *}$ & -9.9 & 0.8 & $0.000^{\star \star}$ \\
\hline C3 profile & -0.2 & 3.1 & $17 \cdot 8$ & 3.2 & $0.000^{* *}$ & $7 \cdot 7$ & 1.7 & $0.029^{*}$ \\
\hline C4 profile & $2 \cdot 1$ & $6 \cdot 1$ & $39 \cdot 2$ & $6 \cdot 0$ & $0.000^{* *}$ & $30 \cdot 9$ & $2 \cdot 9$ & $0.000^{*}$ \\
\hline \multicolumn{9}{|l|}{ Protein metabolites } \\
\hline Phenol ( $\mu \mathrm{g} / \mathrm{g}$ DM) & 0.03 & 0 & 0.03 & 0 & $0.048^{\star}$ & 0.03 & 0 & 0.088 \\
\hline$p$-Cresol ( $\mu \mathrm{g} / \mathrm{g}$ DM) & $56 \cdot 2$ & 5.9 & 39.6 & 3.4 & 0.108 & 41.6 & $3 \cdot 8$ & 0.244 \\
\hline \multicolumn{9}{|l|}{ Enzymatic activities } \\
\hline$\alpha$-Glucosidase ( $\mu \mathrm{g} / \mathrm{g} \mathrm{DM})$ & $170 \cdot 9$ & $16 \cdot 0$ & $271 \cdot 0$ & $25 \cdot 9$ & $0.006^{\star *}$ & 270.8 & $27 \cdot 0$ & $0.005^{\star \star}$ \\
\hline$\beta$-Glucuronidase ( $\mu \mathrm{g} / \mathrm{g}$ DM) & 21.9 & 4.7 & $55 \cdot 0$ & 9.5 & $0.001^{* *}$ & 44.5 & 6.9 & $0.002^{* \star}$ \\
\hline
\end{tabular}

XOS, xylo-oligosaccharide; INU-XOS, inulin-and-XOS mixture.

* Values were significantly different compared to the placebo group $(P<0.05)$.

** Values were significantly different compared to the placebo group $(P<0.01)$.

†For carbohydrate metabolites (SCFA), changes from baseline (percentage change) are presented. For other parameters, when no data are available at $V_{1}$ (measurement done on first day of treatment), absolute measures at $V_{3}$ are presented and used for comparison. These include protein metabolites (phenols) and enzymatic activities. 
Table 7. Parameters linked to the immune modulatory effect at $V_{3}$ (measurement done after 4 weeks of treatment) $\dagger$ (Mean values with their standard errors)

\begin{tabular}{|c|c|c|c|c|c|c|c|c|}
\hline & \multicolumn{2}{|c|}{ Placebo } & \multicolumn{2}{|c|}{ xos } & \multirow[b]{2}{*}{$P$} & \multicolumn{2}{|c|}{ INU-XOS } & \multirow[b]{2}{*}{$P$} \\
\hline & Mean & SEM & Mean & SEM & & Mean & SEM & \\
\hline \multicolumn{9}{|l|}{ Changes in expression } \\
\hline TNF- $\alpha$ & $-19 \cdot 6$ & $27 \cdot 3$ & $2 \cdot 8$ & $27 \cdot 0$ & 0.715 & $-29 \cdot 6$ & $16 \cdot 2$ & 0.753 \\
\hline $\mathrm{IL}-10$ & -0.6 & $24 \cdot 2$ & -33.9 & $29 \cdot 2$ & 0.206 & $-63 \cdot 6$ & $25 \cdot 7$ & 0.078 \\
\hline \multicolumn{9}{|l|}{ Cytokine expression } \\
\hline IL-1 $\beta$ (relative expression) & $9 \cdot 23$ & 0.54 & $8 \cdot 14$ & 0.60 & 0.915 & $7 \cdot 61$ & 0.58 & $0.045^{\star}$ \\
\hline IL-8 (relative expression) & $6 \cdot 26$ & 0.57 & 5.66 & 0.71 & 0.517 & $5 \cdot 34$ & 0.51 & 0.228 \\
\hline IL-12 (relative expression) & 0.49 & 0.49 & -0.23 & 1.15 & 0.613 & -1.15 & 1.06 & 0.213 \\
\hline IFN- $\gamma$ (relative expression) & $3 \cdot 13$ & 0.49 & 3.49 & 0.59 & 0.768 & 3.16 & 0.74 & 0.607 \\
\hline IL-4 (relative expression) & $-5 \cdot 17$ & 0.55 & $-5 \cdot 78$ & 0.61 & 0.685 & -5.42 & 0.72 & 0.685 \\
\hline IL-13 (relative expression) & $-8 \cdot 18$ & 1.06 & $-5 \cdot 88$ & 0.95 & 0.119 & -3.74 & $1 \cdot 11$ & $0.010^{*}$ \\
\hline \multicolumn{9}{|l|}{ Direct parameters } \\
\hline $\mathrm{s}-\lg \mathrm{A}(\mathrm{ng} / \mathrm{ml}$ faecal water) & 1249 & 240 & 1485 & 300 & 0.409 & 1629 & 277 & 0.155 \\
\hline Circulating LPS (EU/ml) & 0.86 & 0.07 & 0.88 & 0.12 & 1.000 & 0.62 & 0.11 & $0.026^{*}$ \\
\hline
\end{tabular}

studies $^{(30,31)}$ and confirmed in the present one. Since XOS are not digestible in the upper intestinal tract, induce an increase of a limited number of potentially beneficial micro-organisms in the colon and produce beneficial effects for the host by the modification of the colonic microflora composition ${ }^{(32)}$, XOS have high prebiotic potential.

Results with XOS are consistent with recent publications $^{(30,31,33)}$ showing a bifidogenic effect of the oligosaccharide. It is interesting to note that under very similar experimental conditions (similar food matrix and target population), we find a much better bifidogenic effect with $5 \mathrm{~g} / \mathrm{d}$ compared to $10 \mathrm{~g} / \mathrm{d}$ consumed by subjects in the study described by Cloetens et al $^{(33-35)}$. The association of inulin and XOS ( 3 and $1 \mathrm{~g} / \mathrm{d}$, respectively) appears to be more efficient than inulin used at higher doses in the literature ${ }^{(26,29)}$ or other non-digestible carbohydrates ${ }^{(36)}$. In the present study, no effect on the lactobacillus population was observed for XOS. Despite the fact that in vitro study on SHIME has shown an increase of Lactobacillus (Y. Dugenet, personal communication). This is consistent with the literature ${ }^{(34)}$. Only a moderate and transient Lactobacillus increase was observed at $\mathrm{V}_{2}$ for the INU-XOS group as compared to the same subjects at $\mathrm{V}_{1}$. Other bacterial species known for their acidophilic and butyrogenic properties in the fermentation of non-digestible fibres were tested, but neither $F$. prausnitzii nor Roseburia spp. was significantly modulated. Peptostreptococcus were moderately but significantly increased at $\mathrm{V}_{2}$ for both test products compared to placebo before returning to control levels by the end of the intervention.

Clostridium population was finally measured as a marker of pathogenic bacteria and was found to significantly decrease with time for both test products. However, this effect was also observed for the placebo, suggesting a role of the orange juice matrix. The lack of effect of either fibre on Clostridium is consistent with the literature on $\mathrm{XOS}^{(30)}$ showing no effect and inulin ${ }^{(26)}$ showing a slight stimulation. It is well known that Bifidobacterium do not produce gas during carbohydrate fermentation, whereas Clostridiae are prolific gas producers $^{(37)}$. It may explain the good tolerance in our study, as discussed next, and it may suggest a decrease of Clostridium population by XOS.

The principal fermentation products of non-digestible carbohydrate-like fructans and arabinoxylans are SCFA, mainly acetate (C2), propionate (C3) and butyrate (C4). A study comparing an arabinoxylan fibre (pentosan) and inulin (at $15 \mathrm{~g} / \mathrm{d}$ ) has shown that arabinoxylan increases more total SCFA and butyrate than inulin ${ }^{(38)}$. The present study shows an increase in total SCFA in the INU-XOS rather than the XOS group, suggesting a role of inulin in this increased production, in opposition to previous reports ${ }^{(38)}$. While both groups showed very similar profiles of SCFA contribution at $\mathrm{V}_{3}$, with an overall decrease of acetate contribution to the benefit of propionate and butyrate, faecal concentration of the individual fatty acids were not identical. Indeed, we observed a switch from acetate to butyrate production for the XOS group, while the acetate production was not affected for the INU-XOS group whereas both propionate and butyrate increased. This suggests the selection of different bacterial strains by XOS and inulin, inducing different fermentation patterns. The physiological consequences of an increase in C3 and $\mathrm{C} 4$ fatty acids may be the reduction of the risks for a number of disorders. For example, butyrate is correlated with lower risks for colorectal cancer ${ }^{(39,40)}$. It may be due in part to a reduction in faecal $\mathrm{pH}$, as observed in the XOS group and in another study using $\mathrm{XOS}^{(30)}$. Lower $\mathrm{pH}$ inhibits the activity of procarcinogenic enzymes ${ }^{(41)}$ as well as the growth of pathogenic putrefaction bacteria ${ }^{(42)}$. The increased propionate:acetate ratio can also play a role in cholesterol metabolism, thus reducing the risks of cardiovascular disorders $^{(43)}$. More recent theories suggest a role of butyrate in energy metabolism, modulating the expression of the 
glucagon-like peptide- $2^{(44)}$. This may reduce the risks of developing obesity and its metabolic complications ${ }^{(45)}$.

Other markers of the colonic microbiota are bacterial enzyme activities and non-fatty bacterial metabolites such as phenol and $p$-cresol. We found an increase in both $\alpha$-glucosidase and $\beta$-glucuronidase activities in the two test groups. Another study ${ }^{(38)}$ has shown no effect on the activity of faecal $\beta$-glucuronidase with inulin or with XOS, but a slight increase in $\beta$-glucosidase activity. Previous studies have shown that FOS and inulin decrease ${ }^{(46,47)}$ or have no effect $^{(48,49)}$ on glucuronidase activity. These results indicate that microflora changes can regulate the synthesis of enzymes involved in the initial hydrolysis of the carbohydrate substrate. The impact of these changes in enzyme activity in relation to gut health is not elucidated, but it has been suggested that these enzymes are involved in the conversion of procarcinogen compounds $^{(6)}$. It is important to note as well that bacteria expressing glucosidase and glucuronidase activity are often butyrogenic $^{(50)}$. Thus, we consider this increase in enzymatic activity as a positive marker of specific bacterial strains rather than a marker of the enzymatic potential.

Only faecal $p$-cresol decreased in the XOS group in our study, whereas in another study a higher concentration of phenols in faeces was found for XOS compared to inulin ${ }^{(38)}$. However, a decrease in urinary $p$-cresol without affecting phenol excretion was observed in another study using $\mathrm{XOS}^{(33)}$. An in vitro model of the proximal colon has shown that inulin lowered $p$-cresol especially in the presence of the pathogenic Clostridium difficile ${ }^{(51)}$. These carcinogenic compounds are the end-products of amino acid fermentation ${ }^{(52)}$ and may be influenced by protein intake.

The present results demonstrate without any doubt that both XOS and INU-XOS have a strong prebiotic effect after 2 and 4 weeks of intake.

Both products and especially XOS are well tolerated. Apart from higher flatulence and bloating in the INU-XOS group, no difference occurs at $\mathrm{V}_{3}$ between the prebiotics group and placebo for the individual digestive symptoms, global digestive tolerance, stool consistency and frequency, and for wellbeing. The small increase in symptoms observed in the INU-XOS group at week 2 completely disappeared by the end of the study. Other studies with short-chain FOS $^{(17)}$ or with other non-digestible carbohydrates ${ }^{(24)}$ have shown the same evolution with a transient impairment of digestive comfort. A study using the same inulin-type fructan (Fibruline $\left.{ }^{(}\right)$ has shown a dose-effect response for digestive tolerance from $5 \mathrm{~g}$ up to $20 \mathrm{~g}^{(52)}$. A study on the lowest bifidogenic dose of inulin $(5 \mathrm{~g} / \mathrm{d})^{(26)}$ found an increase in stool frequency, intestinal bloating and flatulence. On the other hand, a study in elderly subjects has shown no adverse influence of $4 \mathrm{~g}$ XOS on gastrointestinal symptoms and no difference with placebo $^{(30)}$, which is consistent with our findings in the XOS group. We therefore expect that the digestive discomfort observed for INU-XOS is probably due to inulin contribution to the mix.

A secondary objective of the study was to better understand the impact of fibres on the immune system and inflammatory response. Prebiotics, and particularly $\beta(2 \rightarrow 1)$-fructans (e.g. inulin), may have beneficial effects upon immune function and inflammatory process. For instance, several studies $^{(7)}$ in animals report an increase of intestinal or faecal s-IgA levels upon supplementation with various $\beta(2 \rightarrow 1)$ fructans preparation. There are, however, very few studies in human subjects. In one study in newborn infants fed a formula supplemented with a mixture of galacto-oligosaccharides and long-chain inulin, the authors observed an increase in faecal s-IgA ${ }^{(54)}$. In our study, we found a higher but non-significant level of faecal s-IgA in the INU-XOS group. We have shown that LPS were significantly lower in the INU-XOS group at the end of the 4-week study compared to the placebo group. LPS or bacterial endotoxin is a potently inflammatory antigen present in large quantities in the human gut. It is now well known that LPS is a strong stimulator of the release of several cytokines that are key inducers for inflammation, insulin resistance, atherosclerosis and obesity. Toll-like receptor 4 is the specific receptor for $\operatorname{LPS}^{(15,16)}$. Bacterial endotoxin circulates in the plasma of human subjects at low concentrations. The process named metabolic endotoxaemia is the day-to-day impact of LPS on inflammation. In mice, Cani et $a l^{(10,11)}$ suggest a critical role of bacterial LPS from the Gram-negative bacteria in the intestinal tract in the development of obesity. The metabolic concentrations of LPS are modulated by food content ${ }^{(55,56)}$. Indeed, mice fed a high-energy diet showed a higher increase in plasma LPS if the energy source is fat rather than carbohydrate ${ }^{(57)}$. Similarly, a high-fat meal induces low-grade endotoxaemia ${ }^{(12)}$, which may partially explain postprandial inflammation. Moreover, positive correlations were observed between fat and energy intakes ${ }^{(58)}$, and Ghanim et al. ${ }^{(59)}$ observed a significant increase in plasma concentrations of endotoxin and Toll-like receptor 4 expression in peripheral blood mononuclear cells after the intake of high-fat, high-carbohydrate meals. In a mouse model, fructans supplementation to a high-fat diet induced a decrease of plasma LPS and pro-inflammatory cytokines together with the selective increase of bifidobacteria ${ }^{(10)}$. This is, to our knowledge, the first human study investigating the effect of prebiotic fibres on circulating LPS in a population consuming a balanced diet.

A young and healthy population does not show sufficient baseline expression of cytokines to detect significant modulation by the dietary intervention alone. We thus decided to use an ex vivo model using LPS-challenged whole blood collected from subjects included in our study in order to understand the priming of immune response ${ }^{(22)}$. We have shown simultaneously a lower IL-1 $\beta$ and TNF- $\alpha$ expression together with a higher IL-13 and IL-10 expression, suggesting a capacity to reduce the intensity of an acute pro-inflammatory reaction. This modulatory effect was only significant in the INU-XOS group. Further statistical analyses have shown that this effect was not due to lower circulating LPS levels in the plasma but was solely linked to a group effect. Indeed, lower LPS levels could have induced a lower inflammatory status of the subjects and made an impact on the apparent immune modulation to the ex vivo challenge. Because we are dealing with a young and healthy population, circulating levels are probably too low to induce any kind of inflammatory 
response, be it low-grade. We therefore could not link the indirect immune modulation effect to a specific factor. Other fibres such as $\alpha$-glucans from Agaricus bisporus (mushrooms) have recently been shown to lower LPS-induced TNF- $\alpha$ production in slightly hypercholesterolaemic subjects using the same ex vivo challenge ${ }^{(60)}$. In FOS-supplemented female mice, $\mathrm{T}$ cell cytokine production was enhanced with an increase in IL-10 and interferon- $\gamma$ production from stimulated Peyer's patches $\mathrm{CD}^{+} \mathrm{T}$ cells ${ }^{(61)}$. Simultaneously, IL-10 production from Peyer's patches and mesenteric lymph nodes was also increased in rats with oligofructose-enriched inulin supplementation ${ }^{(57,62)}$. Another clinical study shows similar trends towards reduced production of the proinflammatory signalling cytokines in an elderly population by a $\beta$-galacto-oligosaccharide ${ }^{(63)}$. Regarding cytokine expression in elderly adults resident in long-term care facilities, IL-6 production by stimulated blood mononuclear cells was decreased and a trend for a reduced IL-10 production was observed upon FOS supplementation ${ }^{(64)}$. No data were available from clinical trials using XOS or a mixture of inulin and XOS to back up our findings.

Recently, an experimental study showed that orange juice neutralises the pro-inflammatory effect of a high-fat, highcarbohydrate meal and prevents endotoxin increase and Toll-like receptor expression ${ }^{(65)}$. These data were not publicly available at the time of designing of our experimental conditions. Even though some effects may have been masked by the matrix, it only strengthens the immune stimulation observed with INU-XOS as expressed by a difference for cytokines expression and LPS translocation.

This study has demonstrated a clear prebiotic effect of XOS alone and of XOS mixed with inulin. This was proven both through changes in the composition of the colonic microflora and its metabolic activities. In addition, we have shown that prebiotic fibres may reduce the pro-inflammatory response and decrease LPS translocation while improving s-IgA secretion into the lumen. This, to our knowledge, is the first clinical study showing an anti-inflammatory potential in healthy volunteers consuming a balanced diet enriched with a mixture of prebiotic fibres.

The next step would be to investigate whether greater changes may occur in subjects presenting a low-grade systemic inflammation such as in obesity, and the metabolic syndrome ${ }^{(66)}$, since it is suggested that inflammation linked to a high-fat diet is induced by LPS $^{(56)}$. Moreover, it would be interesting to look at the impact on weight loss and improvement of metabolic disturbances using supplementation of INU-XOS fibres together with a moderate low-energy and low-fat diet. We could then tackle important mechanisms for the management or prevention of obesity, the metabolic syndrome, diabetes, CVD or even sarcopenia. Further studies are needed to understand the beneficial effects to specific target populations.

\section{Acknowledgements}

We thank Yann Dugenet, chairman of Witaxos DF3 SAS, for funding this research programme. We also thank
Bruno Cadiou and Pascale Dartois for their helpful coordination and the nursing students at the Beauvais Hospital for their involvement in blood sampling. We would like to acknowledge as well the medical support from Dr Aurélie Dornier-Fehre and Sophie Bontemps, who closely followedup on the volunteers throughout the clinical trial. We are grateful for the help provided by Hélène Mauprivez in the preparation phase of the study. Finally, we thank the dietitian Sylvie Bal from the Institut Pasteur de Lille for her work in the preparation and analysis of the dietary data. Y. D. was the sponsor and Cosucra Company (represented by H. J.) participated in this trial. J.-M. L. was the investigator of the study. J.-M. L. and F. D. participated equally in the writing of the manuscript. G. L. was the co-investigator. P. R. P. was the scientific coordination manager while A. C., E. C., F. D. and G. A. were study managers. A. M. A. performed molecular diagnostic experiments. L. R. was in charge of analytical chemistry experiments and C. N. N. performed the statistical analyses. H. Y. was in charge of the monitoring and A. J. helped to review the manuscript. Witaxos DF3 SAS funded the present study, which could represent a conflict of interest. Except for that, the authors have no conflicts of interest to declare.

\section{References}

1. Bik EM (2009) Composition and function of the human associated microbiota. Nutr Rev 67, S164-S171.

2. DiBaise JK, Zhang H, Crowell MD, et al. (2008) Gut microbiota and its possible relationship with obesity. Mayo Clin Proc 83, 460-469.

3. Gibson GR \& Roberfroid MB (1995) Dietary modulation of the human colonic microbiota: introducing the concept of prebiotics. J Nutr 125, 1401-1412.

4. Gibson GR, Probert HM, Loo JV, et al. (2004) Dietary modulation of the human colonic microbiota: updating the concept of prebiotics. Nutr Res Rev 17, 259-279.

5. Roberfroid M, Gibson GR, Hoyles L, et al. (2010) Prebiotic effects: metabolic and health benefits. Br J Nutr 104, Suppl. S2, S1-S63.

6. Roberfroid MB, Bornet F, Bouley C, et al. (1995) Colonic microflora: nutrition and health. Summary and conclusions of an International Life Sciences Institute (ILSI) [Europe] workshop held in Barcelona, Spain. Nutr Rev 53, 127-130.

7. Lomax AR \& Calder PC (2009) Prebiotics, immune function, infection and inflammation: a review of the evidence. $\mathrm{BrJ}$ Nutr 101, 633-658.

8. Hotamisligil GS (2006) Inflammation and metabolic disorders. Nature 444, 860-867.

9. Creely SJ, McTernan PG, Kusminski CM, et al. (2007) Lipopolysaccharide activates an innate immune system response in human adipose tissue in obesity and type 2 diabetes. $A m \mathrm{~J}$ Physiol Endocrinol Metab 292, E740-E747.

10. Cani PD, Neyrinck AM, Fava F, et al. (2007) Selective increases of bifidobacteria in gut microflora improve highfat-diet-induced diabetes in mice though a mechanism associated with endotoxaemia. Diabetologia 50, 2374-2383.

11. Cani PD, Bibiloni R, Knauf C, et al. (2008) Changes in gut microbiota control metabolic endotoxemia induced inflammation in high fat diet induced obesity and diabetes in mice. Diabetes 57, 1470-1481. 
12. Erridge C, Attina T, Spickett CM, et al. (2007) A high-fat meal induces low-grade endotoxemia: evidence of a novel mechanism of postprandial inflammation. Am J Clin Nutr 86, 1286-1292.

13. Hotamisligil GS \& Erbay E (2008) Nutrient sensing and inflammation in metabolic diseases. Nat Rev Immunol 8, 923-934.

14. Shoelson SE \& Goldfine AB (2009) Getting away from glucose: fanning the flames of obesity-induced inflammation. Nat Med 15, 373-974.

15. Chow JC, Young DW, Golenbock DT, et al. (1999) Toll-like receptor- 4 mediates lipopolysaccharide-induced signal transduction. J Biol Chem 274, 10689-10692.

16. Wright SD, Ramos RA, Tobias PS, et al. (1990) CD14, a receptor for complexes of lipopolysaccharide (LPS) and LPS binding protein. Science 249, 1431-1433.

17. Paineau D, Payen F, Panserieu S, et al. (2008) The effects of regular consumption of short-chain fructo-oligosaccharides on digestive comfort of subjects with minor functional bowel disorders. Br J Nutr 99, 311-318.

18. Pouillart PR, Dépeint F, Abdelnour A, et al. (2010) Nutriose, a prebiotic low-digestible carbohydrate, stimulates gut mucosal immunity and prevents TNBS-induced colitis in piglets. Inflamm Bowel Dis 16, 783-794.

19. Scheppach WM, Fabian CE \& Kasper HW (1987) Fecal shortchain fatty acid (SCFA) analysis by capillary gas-liquid chromatography. Am J Clin Nutr 46, 641-646.

20. Birkett AM, Jones GP \& Muir JG (1995) Simple highperformance liquid chromatographic analysis of phenol and $p$-cresol in urine and feces. J Chromatogr Biomed Appl 674, 187-191.

21. Djouzi Z, Andrieux C, Degivry MC, et al. (1997) The association of yogurt starters with Lactobacillus casei DN 114.001 in fermented milk alters the composition and metabolism of intestinal microflora in germ-free rats and in human flora-associated rats. J Nutr 127, 2260-2266.

22. Abdel Nour AM, Dépeint F, Barbour EK, et al. (2010) Ex-vivo LPS stimulation model coupled with quantitative PCR and its multispecies application in immunonutrition. Eur Pharm Rev Dig 15, 31-35.

23. Agence nationale de sécurité sanitaire Alimentation, Environnement, Travail (2008) French food composition table CIQUAL 2008. http://www.afssa.fr/TableCIQUAL

24. Bouhnik Y, Raskine L, Simoneau G, et al. (2004) The capacity of nondigestible carbohydrates to stimulate fecal bifidobacteria in healthy humans: a double-blind, randomized, placebo-controlled, parallel-group, dose-response relation study. Am J Clin Nutr 80, 1658-1664.

25. Bach Knudsen KE \& Hessov I (1995) Recovery of inulin from Jerusalem artichoke (Helianthus tuberosus L.) in the small intestine of man. Br J Nutr 74, 101-113.

26. Kolida S, Meyer D \& Gibson GR (2007) A double-blind placebo-controlled study to establish the bifidogenic dose of inulin in healthy humans. Eur J Clin Nutr 60, 1189-1195.

27. Bouhnik Y, Raskine L, Champion K, et al. (2007) Prolonged administration of low-dose inulin stimulates the growth of bifidobacteria in humans. Nutr Res 27, 187-193.

28. Marteau P, Jacobs H, Cazaubiel M, et al. (2011) Effects of chicory inulin in constipated elderly people: a doubleblind controlled trial. Int J Food Sci Nutr 62, 164-170.

29. Meyer D \& Stasse-Wolthuis M (2009) The bifidogenic effect of inulin and oligofructose and its consequences for gut health. Eur J Clin Nutr 63, 1277-1289.

30. Chung YC, Hsu CK, Ko CY, et al. (2007) Dietary intake of xylooligosaccharides improves the intestinal microbiota, fecal moisture, and $\mathrm{pH}$ value in the elderly. Nutr Res $\mathbf{2 7}$, $756-761$.

31. Grootaert C, Delcour JA, Courtin CM, et al. (2007) Microbial metabolism and prebiotic potency of arabinoxylan oligosaccharides in the human intestine. Trends Food $\mathrm{Sci}$ Technol 18, 64-71.

32. Yamada H, Itoh K, Morishita Y, et al. (1993) Structure and properties of oligosaccharides from wheat bran. In Symposium on Technical Advances in Japan: The American Association of Cereal Chemistry (AACC), Annual Meeting, Minneapolis, $\mathrm{MN}$

33. Cloetens L (2009) In vivo evaluation of the gastrointestinal effects of arabinoxylan-oligosaccharides in healthy subjects. PhD Thesis, Katholieke Universiteit Leuven.

34. Cloetens L, Broekaert WF, Delaedt Y, et al. (2010) Tolerance of arabinoxylan-oligosaccharides and their prebiotic activity in healthy subjects: a randomised, placebo-controlled cross-over study. Br J Nutr 103, 703-713.

35. Cloetens L, De Preter V, Swennen K, et al. (2008) Doseresponse effect of arabinoxylooligosaccharides on gastrointestinal motility and on colonic bacterial metabolism in healthy volunteers. J Am Coll Nutr 27, 512-518.

36. Pasman W, Wills D, Saniez MH, et al. (2006) Long-term gastrointestinal tolerance of NUTRIOSE FB in healthy men. Eur J Clin Nutr 60, 1024-1034.

37. Louis P \& Flint HJ (2009) Diversity, metabolism and microbial ecology of butyrate-producing bacteria from the human large intestine. FEMS Microbiol Lett 294, 1-8.

38. Grasten S, Liukkonen KH, Chrevatidis A, et al. (2003) Effects of wheat pentosan and inulin on the metabolic activity of fecal microbiota and on bowel function in healthy humans. Nutr Res 23, 1503-1514.

39. Pouillart PR (1998) Role of butyric acid and its derivatives in the treatment of colorectal cancer and hemoglobinopathies. Life Sci 63, 1739-1760.

40. Pool-Zobel BL (2005) Inulin-type fructans and reduction in colon cancer risk: review of experimental and human data. Br J Nutr 93, Suppl. 1, S73-S90.

41. Wollowski I, Rechkemmer G \& Pool-Zobel BL (2001) Protective role of probiotics and prebiotics in colon cancer. $\mathrm{Am} \mathrm{J}$ Clin Nutr 73, 451S-455S.

42. Gibson GR \& Wang X (1994) Regulatory effects of bifidobacteria on the growth of other colonic bacteria. J Appl Bacteriol 77, 412-420.

43. Wong JM, de Souza R, Kendall CW, et al. (2006) Colonic health: fermentation and short chain fatty acids. J Clin Gastroenterol 40, 235-243.

44. Delzenne NM \& Cani PD (2010) Nutritional modulation of gut microbiota in the context of obesity and insulin resistance: potential interest of prebiotics. Int Dairy $J \mathbf{2 0}$, $277-280$

45. Cani PD \& Delzenne NM (2009) Interplay between obesity and associated metabolic disorders: new insights into the gut microbiota. Curr Opin Pharmacol 9, 737-743.

46. Van Dokkum W, Wezendonk B, Srikumar TS, et al. (1999) Effect of nondigestible oligosaccharides on large-bowel functions, blood lipid concentrations and glucose absorption in young healthy male subjects. Eur J Clin Nutr 53, 1-7.

47. Buddington RK, Williams CH, Chen SC, et al. (1996) Dietary supplement of neosugar alters the fecal flora and decreases activities of some reductive enzymes in human subjects. Am J Clin Nutr 63, 709-716.

48. Kleessen B, Sykura B, Zunft HJ, et al. (1997) Effects of inulin and lactose on fecal microflora, microbial activity, and bowel habit in elderly constipated persons. Am J Clin Nutr 65 1397-1402. 
49. Bouhnik Y, Flourié B \& Riottot M (1996) Effects of fructooligosaccharides ingestion on fecal bifidobacteria and selected metabolic indexes of colon carcinogenesis in healthy humans. Nutr Cancer 26, 21-29.

50. Dabek M, McCrae SI, Stevens VJ, et al. (2008) Distribution of beta-glucosidase and beta-glucuronidase activity and of beta-glucuronidase gene gus in human colonic bacteria. FEMS Microbiol Ecol 66, 487-495.

51. Van Nuenen M, Meyer D \& Venema K (2003) The effect of various inulins and Clostridium difficile on the metabolic activity of the human colonic microbiote in vitro. Microb Ecol Health Dis 15, 137-144.

52. Gibson GR \& Macfarlane GT (1995) Human colonic bacteria role in nutrition, physiology and pathology. In Human Colonic Bacteria: Role in Nutrition, Physiology and Pathology, pp. 75-100 [GR Gibson and GT Macfarlane, editors]. Boca Raton, FL: CRC Press.

53. Bruhwyler J, Carreer F, Demanet E, et al. (2008) Digestive tolerance of inulin-type fructans: a double-blind, placebocontrolled, cross-over, dose-ranging, randomized study in healthy volunteers. Int J Food Sci Nutr 12, 1-11.

54. Bakker-Zierikzee AM, Tol EA, Kroes H, et al. (2006) Faecal SIgA secretion in infants fed on pre- or probiotic infant formula. Pediatr Allergy Immunol 17, 134-140.

55. Turnbaugh PJ, Ley RE, Mahowald MA, et al. (2006) An obesity associated gut microbiome with increased capacity for every harvest. Nature 444, 1027-1031.

56. Cani P, Amar J, Iglesias MA, et al. (2007) Metabolic endotoxemia initiates obesity and insulin resistance. Diabetes $\mathbf{5 6}$, 1761-1772.

57. Roller M, Pietro Femia A, Caderni G, et al. (2004) Intestinal immunity of rats with colon cancer is modulated by oligofructose-enriched inulin combined with Lactobacillus rhamnosus and Bifidobacterium lactis. Br J Nutr $\mathbf{9 2}$ 931-938

58. Amar J, Burcelin R, Ruidavets JB, et al. (2008) Energy intake is associated with endotoxemia in apparently healthy men. Am J Clin Nutr 87, 1219-1923.
59. Ghanim H, Abuaysheh S, Sia CL, et al. (2009) Increase in plasma endotoxin concentrations and the expression of Toll-like receptors and suppressor of cytokine signaling-3 in mononuclear cells after a high-fat, high-carbohydrate meal: implications for inulin resistance. Diabetes Care 32, 2281-2287.

60. Volman JJ, Mensink RP, van Griensven LJ, et al. (2010) Effects of alpha-glucans from Agaricus bisporus on ex vivo cytokine production by LPS and PHA-stimulated PBMCs, a placebocontrolled study in slightly hypercholesterolemic subjects. Eur J Clin Nutr 64, 720-726.

61. Hosono A, Ozawa A \& Kato R (2003) Dietary fructooligosaccharides induce immunoregulation of intestinal IgA secretion by murine Peyer's patch cells. Biosci Biotechnol Biochem 67 , 758-764.

62. Roller M, Rechkemmer G \& Watzl B (2004) Prebiotic inulin enriched with oligofructose in combination with the probiotics Lactobacillus rhammosus and Bifidacterium lactis modulates intestinal immune functions in rats. J Nutr $\mathbf{1 3 4}$, 153-156.

63. Vulevic J, Drakoularakou A, Yaqoob P, et al. (2008) Modulation of the fecal microflora profile and immune function by a novel trans-galactooligosaccharide mixture (B-GOS) in healthy elderly volunteers. Am J Clin Nutr 88, 1438-1446.

64. Langkamp-Henken B, Wood SM, Herlinger-Garcia KA, et al. (2006) Nutritional formula improved immune profiles of seniors living in nursing homes. J Am Geriatr Soc 54, $1861-1870$

65. Ghanim H, Sia CL, Upadhyay M, et al. (2010) Orange juice neutralizes the proinflammatory effect of a high-fat, highcarbohydrate meal and prevents endotoxin increase and Toll-like receptor expression. Am J Clin Nutr 91, 940-949.

66. Alvarez J, Higgins PB, Oster RA, et al. (2009) Fasting and postprandial markers of inflammation in lean and overweight children. Am J Clin Nutr 89, 1138-1144. 